\title{
Questões metodológicas da pesquisa de campo em comunicação organizacional: um olhar a partir da microssociologia de Goffman
}

\section{Methodological questions of fieldwork in organizational communication research: an approach from Goffman's microsociology}

Luis Mauro Sá Martino ${ }^{1}$

Ana Paula Santos ${ }^{2}$

Resumo: Este artigo discute aspectos metodológicos de uma pesquisa de campo realizada de agosto de 2018 a fevereiro de 2019, como parte de um estudo sobre a comunicação face a face em uma empresa. Foram estudados episódios interacionais durante 12 reuniões de um comitê de projeto, focalizando as interações em microescala. Durante o período de observação, no entanto, surgiram várias questões metodológicas, discutidas aqui a partir dos trabalhos de Erving Goffman, uma das referências da pesquisa: (a) existe um método "goffmaniano" para micro-observação? (b) Como observar os eventos de microescala quando se faz parte dela? (c) Como elaborar uma descrição válida do que foi visto? Estas questões são pensadas como parte de uma discussão epistemológica sobre métodos de pesquisa em comunicação.

Palavras-chave: comunicação organizacional; metodologia; pesquisa de campo; Goffman.

Abstract: This paper discusses some methodological aspects of a field research conducted from August 2018 to February 2019, as part of a broader study about face to face communication in a company. It studied interactional episodes during 12 meetings of a project board, focusing on the micro-scale interactions. However, during the study, several methodological issues have arisen, some of them stirred

1 Faculdade Cásper Líbero (FCL). São Paulo, SP, Brasil.

https://orcid.org/0000-0002-5099-1741. E-mail: lmsamartino@gmail.com

2 Faculdade Cásper Líbero (FCL). São Paulo, SP, Brasil.

https://orcid.org/0000-0002-4752-8000 E-mail: msg.anapaula@gmail.com 
62 QUESTÕESMETODOLÓGICASDAPESQUISADECAMPOEMCOMUNICAÇÃOORGANIZACIONAL

by the works of Erving Goffman, which had provided some initial insights for field research: (a) is there a 'goffmanian' method for micro-observation? (b) How to observe the micro-scale events and simultaneously being part of it? (c) How to register the observation findings' in a valid description of what have been seen? This paper addresses these questions as part of a epistemological discussion on communication research methods.

Keywords: organizational communication; research methods; fieldwork; Goffman. 


\section{Introdução}

Este artigo nasce de uma questão prática de pesquisa, surgida ainda durante os primeiros estágios de seu planejamento e realização. Trata-se de uma pesquisa de pós-graduação sobre comunicação organizacional, focalizando nas interações face a face em reuniões e encontros sociais no ambiente de trabalho. O objetivo era observar as modalidades de comunicação no ambiente organizacional a partir das interações face a face entre funcionários de uma empresa do setor elétrico, discutida em outros momentos - por exemplo, em Santos (2018).

Dentre as várias autoras e autores que poderiam ser acionados para um estudo desse tipo, e entendendo, com Braga (2011), o processo de pesquisa como "tomada de decisões", optou-se desde o início por uma aproximação com os estudos de Erving Goffman, sobretudo pela perspectiva metodológica adotada, a observação em escala micro. Essa opção, se por um lado parecia ser coerente em termos da dimensão do objeto de pesquisa, por outro lado levantava uma série de questionamentos sobre os aspectos práticos da pesquisa.

A pesquisa de campo, realizada entre agosto de 2018 e fevereiro de 2019, provocou alguns tensionamentos entre o cotidiano das observações e as questões metodológicas estudadas, que podem ser expressas na forma de três questões: (1) existe um método "goffmaniano" para observação em escala micro? (2) Como observar os eventos de microescala e fazer parte dela? (3) Como registrar os achados da observação em uma descrição válida do que foi visto? No que se segue, este texto procura delinear essas perguntas - mais do que indicar qualquer resposta fechada - articulando os problemas práticos que surgiram durante a pesquisa de campo com indicações metodológicas pensadas a partir da obra de Goffman.

Valem, de saída, algumas notas.

Há vários trabalhos relacionados à observação e à pesquisa participante, como Brandão (1999), Lüdke e André (1986), Gajardo (1986) e Vianna (2003), entre outros, que dimensionam pontos importantes sobre práticas metodológicas, oferecendo um suporte conceitual e 
prático acerca dos procedimentos desse tipo de pesquisa sem endereçar, no entanto, questões voltadas para o aspecto comunicacional das microinterações. Este texto não procura fazer uma discussão desse tipo de método em si, mas apenas na medida em que se aproxima da pesquisa realizada.

Não há pretensão de ineditismo ao trazer as análises de Goffman para o estudo da comunicação em contextos organizacionais, algo já feito por outros trabalhos. Como indica Maria Gabriela Gama (2005, p. 1885), "tal como a sociedade, as empresas são realidades socialmente construídas. Por isso, elas podem ser entendidas como microsociedades onde podem ser estudados os processos de interacção social". A título de exemplo, pensando Goffman no contexto organizacional, Flecha e Machado (2008) mostram como a interação entre empresário e consultor se desenvolve em uma postura de representação e autorrepresentação altamente ritualizada. Por seu turno, Ferreira (2017, p. 9) indica que esse tipo de abordagem "para o entendimento dos processos de comunicação no contexto organizacional é possível e viável por meio do viés microssociológico" de Goffman, "caracterizados pela sua análise das infinitas interações construtoras da vida cotidiana”, desenvolvido em outro texto de Ferreira (2018), analisando uma publicação feita pelos funcionários de uma empresa.

A visada aqui, no entanto, procura se concentrar na questão metodológica que, embora tangenciada pelas pesquisas mencionadas, não parece ser diretamente endereçada.

Do mesmo modo, não é o objetivo aqui fazer uma interpretação dos textos de Goffman ou mesmo um estudo sobre suas questões metodológicas. É um esboço tentativo de compreender e encaminhar algumas questões nascidas da prática cotidiana de pesquisa em conjunto com alguns aspectos de sua obra.

Finalmente, o texto procura colocar um método em discussão, empregado em uma pesquisa de alcance limitado, e não propor uma prática metodológica ou, menos ainda, um "como fazer". É como participantes 
do campo, em uma preocupação dialógica com as questões de método, que se compartilham estas questões.

\section{0 método em escala micro}

Até que ponto é possível falar em uma "metodologia" a partir das obras de Goffman? A apreensão de seus conceitos na pesquisa em Comunicação parece estar relativamente consolidada, como indicam Gastaldo (2004), Ytreberg (2004) e Leeds-Hurwitz (2004). No entanto, a essa apropriação conceitual de Goffman não parece se seguir, na mesma proporção, uma discussão propriamente metodológica de sua obra, que permitisse acionar alguns de seus procedimentos nas práticas de pesquisa.

Mesmo um comentarista da produção de Goffman, como Winkin (1999), considera o que parece ser um paradoxo de sua obra: apesar da sua relevância, disseminação e mesmo popularidade - se esse termo pode ser usado - nas ciências sociais, há poucos continuadores de seu trabalho, ou mesmo pesquisas que se pautem em seus métodos.

Se, por um lado, pode certamente estar relacionado com certa postura do próprio Goffman (segundo comentaristas como Winkin (2004), um ótimo professor, mas não exatamente interessado em formar pesquisadoras e pesquisadores de acordo com seus métodos), parece ser excessivo creditar a uma questão de estilo pessoal a ausência de continuadores diretos.

Vale, nesse ponto, adiantar as inquietações de origem deste trabalho: em que medida é possível acionar um ponto de vista metodológico a partir de Goffman em uma pesquisa em Comunicação? Isso remete a outra pergunta: até que ponto faz sentido falar em um "método" ou "metodologia" de Goffman (ou, em um jogo de palavras talvez mais problemático, uma metodologia "goffmaniana”?). Em termos práticos, como trabalhar com Goffman em uma pesquisa em Comunicação? Qual é seu modo de abordagem do real para a articulação com a prática de pesquisa? Finalmente, uma pergunta de base: quais seriam as metodologias do próprio Goffman? 
A resposta para esta última questão apresenta uma dificuldade adicional: a ausência de escritos metodológicos de Goffman. Ao que tudo indica, não há, em sua produção, obras de reflexão e comentário sobre seus procedimentos, indicações sobre metodologia ou considerações teórico-epistemológicas mais extensas. Assim, falar sobre uma "metodologia” de Goffman significa também fazer um exercício de abstração e reconstrução metodológica a partir de sua obra publicada.

Ou, no caso, de "metodologias", no plural: se é possível observar a presença de alguns temas ao longo de sua obra, em particular uma preocupação com o "infinitamente pequeno", como recorda Bourdieu (2004), as técnicas de pesquisa variam desde a observação de campo (em "A representação do Eu na vida cotidiana”, "Comportamento em lugares públicos" e "Rituais de Interação") passando pela imersão institucional ("Manicômios, prisões e conventos") e pela análise de documentos ("Os quadros da experiência cotidiana", "Gender advertising" e alguns trechos de "Forms of Talk").

Portanto, seguindo algumas das questões metodológicas levantadas por Braga (2010; 2011), no sentido de tomar a comunicação como "disciplina indiciária", podemos procurar "indícios goffmanianos" na reflexão sobre uma prática de pesquisa orientada - talvez a expressão fosse "inspirada", menos precisa, porém mais realista - por algumas de suas proposições. Trata-se, aqui, de uma reflexão sobre procedimentos metodológicos feitos durante e imediatamente depois de um período de pesquisa de campo, entretecida nas relações de pesquisa e orientação. É um olhar para o que Bourdieu (1983, p. 128) denomina a "cozinha das ciências" - no caso, se vale a metáfora, durante a "preparação" da pesquisa, com a pesquisa em ação.

\section{Observador e participar da cena: o choque entre personas}

Em agosto de 2018, questões metodológicas eram uma dúvida que rodeava a formulação de um estudo de caso sobre as interações realizadas 
entre os funcionários de uma organização do setor elétrico. Naquele ano, a empresa iniciou um processo de mudança no modelo de gestão, aqui intitulado "Programa". A iniciativa, segundo a companhia, procurava reformular processos, instaurar novas práticas e transformar a cultura organizacional, mudando a maneira de as pessoas trabalharem e se relacionarem dentro e fora da instituição, com o objetivo de tornar a atuação da empresa mais orientada às necessidades dos clientes externos.

Esse processo seria implementado a partir de uma série de reuniões, conduzidas preferencialmente pelo líder do projeto, com sua equipe principal, secundada por participações adjacentes. O sucesso do projeto estava, portanto, ligado às condições, momentos e contradições existentes em vários momentos, mas focados principalmente durante as reuniões - daí a escolha metodológica de observar essa interação e algumas outras que gravitam em torno dessa, como momentos de descontração ("pausa para um café") e encontros de corredor.

Enquanto as comunicações mediadas pelas tecnologias contam com um diversificado aparato teórico-metodológico para suportar investigação dos fenômenos, o que temos em mãos para apreender o processo comunicacional quando a face de um humano encontra a face do outro?

Goffman parece ser, sobretudo, um pesquisador da interação face a face. Dentro dos procedimentos comuns de orientação, quando se definiu a proposta de pesquisa como sendo "o lugar da comunicação face a face” em situações do universo da Comunicação Organizacional, a própria escolha do vocabulário parecia remeter a Goffman.

Como observa Winkin (1999), em um curioso arco, a produção de Goffman começa e termina com textos intitulados "Interação Social". A expressão aparece em um capítulo de sua tese de doutorado sobre as ilhas Hébridas, na Escócia, e é também o título do que seria a conferência inaugural como presidente da Associação Norte-Americana de Sociologia - Goffman faleceu antes de proferi-la. O conceito reaparece sistematicamente em vários momentos de sua obra, seja de maneira explícita, como no livro Ritual de Interação, seja como fundamento 
implícito de seus procedimentos, como em Comportamento em lugares públicos, Relations in public ou Encounters $\mathrm{O}$ conceito de "interação social" parece se revestir, portanto, de toda uma importância para Goffman, interessado em compreender, em termos mínimos, os elementos presentes em cada uma dessas situações.

Metodologicamente, esse tipo de preocupação poderia ser traduzido na observação e análise de diversos ambientes onde se processam interações e, aparentemente, não há efetivamente uma necessidade de se optar por uma escala "micro" em termos quantitativos. A sociologia dos grupos e das instituições, desenvolvida na época por vários outros sociólogas e sociólogos a partir das matrizes mais diversas, da psicologia social à sociologia quantitativa, poderia dar conta de objetos semelhantes se a questão fosse a dimensão do grupo ou da situação.

O estudo de caso se propôs responder à seguinte pergunta: quando há um movimento de mudança no modelo de gestão de uma organização, como acontecem as interações entre os indivíduos daquele meio? E mais especificamente: quais são os objetivos, estratégias, relações estabelecidas entre os participantes, redes de poder, embates, negociações e táticas de ajuste; e como os discursos ganham força a partir dessas interações?

Em A Representação do Eu na Vida Cotidiana, Goffman (1985) apresenta os resultados de uma pesquisa etnográfica que realizou para sua tese de doutorado na década de 1950, em que analisou as interações face a face de membros de uma comunidade agrícola nas ilhas Shetland, no Reino Unido.

Goffman cria uma série de conceitos a partir das metáforas teatrais para estudar a vida social cotidiana, jogando luz nos detalhes das interações entre indivíduos e suas dinâmicas. "O relacionamento comum é montado tal como uma cena teatral, resultado da troca de ações, oposições e respostas conclusivas dramaticamente distendidas", explica Goffman (1985, p. 71).

Com Goffman em mãos, escolhemos o procedimento metodológico etnográfico de observação participante para realizar o estudo de caso. 
A opção se mostrou absolutamente necessária, uma vez que esta pesquisadora trabalha na Empresa e faz parte do programa, atuando como analista de comunicação institucional.

Schegloff (1988, p. 101) indica também essa proximidade entre sujeito e objeto no centro da própria metodologia de Goffman, sobretudo no sentido de permitir invocar, durante sua leitura, nossas próprias experiências. Essa pergunta metodológica também é feita por Blitvich (2013, p. 9) em um estudo sobre face e identidade, destacando não o aspecto de "método", mas uma "prática” das teorias de Goffman.

O momento da observação e a imersão no campo parecem se apresentar para Goffman como oportunidades de encontrar sentidos inicialmente invisíveis nas trocas e interações, mas que se mostram fundamentais na elaboração das relações cotidianas como marcadores de sentidos, posições e ações no mundo social.

A identificação de significados desvela o que o cotidiano encobre - todo um jogo de sinalizações, indicações, ancoragens, elaboração e reelaboração de argumentos, estratégias para construir as percepções desejadas a respeito de si (e evitar qualquer elemento que rompa com esse “script" previamente definido), delimitação de territórios, atribuições e autoatribuições de valor e importância expressos nos mínimos gestos e atitudes.

Dessa maneira, dentro de uma perspectiva de Goffman, seria possível, a título de exemplo, encontrar expressões de poder - ou de resistência a ele - no ato de cruzar os braços e recostar-se na cadeira durante uma reunião, respirar mais fundo durante um diálogo ou sistematicamente dirigir o olhar para outros pontos que não seu interlocutor ao longo de uma conversa.

O primeiro passo foi obter o consentimento formal do responsável legal da organização, o presidente do Conselho de Administração da Empresa; do líder do programa a ser observado, o gerente executivo de Atendimento; e da gerente executiva de Comunicação. Todos assinaram um termo de autorização. 
Na sequência foi enviado um e-mail para os participantes do encontro informando sobre a observação participante. Nesta comunicação, foi solicitada a manifestação daqueles que eventualmente não se sentissem confortáveis com o procedimento. Não houve nenhum tipo de objeção. Ao contrário, a maior parte realizou comentários amistosos, colocando-se à disposição para auxiliar no que fosse necessário.

Em todas as solicitações, foi enviado anexo um resumo do projeto com os objetivos da pesquisa, para que os envolvidos soubessem mais sobre o estudo de caso e quais seus propósitos.

À primeira vista, o fato de uma das autoras deste texto trabalhar na empresa pareceu-nos uma condição facilitadora e, ao mesmo tempo, dificultadora da observação participante. O fato de ser funcionária da organização há mais de uma década pode ter facilitado o consentimento, por possíveis laços de confiança resultantes do relacionamento profissional que ela possui com os executivos que autorizaram o estudo; e também porque outros funcionários da instituição realizaram anteriormente pesquisas envolvendo a Empresa em dissertações de mestrado e teses doutorado. Já havia, portanto, uma disposição em permitir que funcionários realizassem esse tipo de atividade.

Por outro lado, isso implicava uma questão de distanciamento em relação ao objeto, problema aparentemente bastante explorado em textos sobre metodologia - por exemplo, Corazza (1996), Martinelli (1999), Martino e Marques (2018), Martino (2018) - a respeito da dupla abordagem do pesquisador como sujeito da situação que busca investigar. No caso, ter uma função dupla nos encontros, de observadora de campo e ao mesmo tempo de analista de comunicação da Empresa, pode ter dificultado em certa medida a própria observação, já que a pesquisadora precisou, ao mesmo tempo, observar a cena e atuar profissionalmente, dividindo a sua atenção. Deparamo-nos, ironicamente, com um dilema goffmaniano dado pelo cruzamento das personas acadêmica e profissional. 


\section{As estratégias de observação: pensando com Goffman}

Uma estratégia para lidar com esta questão foi elaborar um instrumento de coleta que direcionasse o olhar para as questões a serem investigadas. A necessidade de um instrumento específico também se deu pelo desafio de observar os fluxos comunicacionais nas interações face a face. Há uma multiplicidade de fenômenos simultâneos que ocorrem na comunicação direta, desde a configuração espacial, os objetos, as roupas, os gestos, as posturas, os humores, o tom das vozes e tantos outros elementos e interditos. É fácil se perder, daí a importância de saber para onde olhar.

Não perder de vista os propósitos investigativos do estudo de caso também foi uma preocupação. Antes de entrar em cada reunião, escrevíamos no caderno as perguntas norteadoras da pesquisa. Na infinidade dos microacontecimentos, não se podia esquecer o objetivo de apreender o papel de cada participante na interação e suas táticas comunicacionais; se foram bem-sucedidas ou não; como a reação de um afetava ou mudava a tática do outro; quais eram os momentos de tensão e, finalmente, que vínculos se formavam ao final de uma dinâmica interacional.

A opção pela observação de uma situação fechada procura levar em consideração a delimitação de uma situação específica, definida de maneira semelhante pelas pessoas que participam dela, daí a opção por estudar interações relativamente limitadas no tempo e no espaço, procurando ver como, no fragmento da interação, emergem mudanças, significados, expectativas, os turnos de interação, reelaboração de representações, revelação de bastidores ou compartilhamento de inferências entre os participantes - e estas afirmações pautam-se parcialmente em Sanders (2012). Como indica Marta Dynel (2011, p. 463), Goffman se concentra no todo das situações sociais, procurando ver o conjunto como uma composição de detalhes.

A observação conduzida por Goffman em suas análises parece envolver, em primeiro lugar, um longo período de campo, com uma imersão parcial, quando não inteira, em seu universo de pesquisa. Trata-se de observações minuciosas de longo prazo, procurando encontrar as formas 
de interação nas situações mais cotidianas, deixando-se levar pela dinâmica de seu objeto de pesquisa naquele momento.

Um problema epistemológico na definição do que poderia ser uma metodologia de Goffman (ou, mais ainda, "goffmaniana") implica o que parece ser uma constante recusa em fazer uma preparação metodológica prévia para o tempo da pesquisa de campo. Antes, ele parece, em cada uma de suas pesquisas, se deixar envolver pelas condições específicas de cada espaço de pesquisa, revendo suas categorias de análise de maneira a não tentar apreender o objeto em interpretações anteriores porque construídas e dirigidas a outros objetos. A especificidade de suas pesquisas, ao que parece, tinha implicações metodológicas diretas na medida em que a compreensão das interações sociais em cada situação correspondia à formulação de categorias próprias que dessem conta do que estava sendo observado.

Não por acaso, como também assinalam Winkin (1999), Winkin e Leeds-Hurwitz (2013) ou Nizet e Rigaux (2016), raramente Goffman transpõe conceitos de um livro para outro, o que não significa, por outro lado, a ausência de coerência em suas análises: Goffman parece se recusar a encontrar "propriedades gerais" das situações - no sentido em que Bourdieu (1983, p. 89) fala em "propriedades gerais dos campos" -, mas encontrar elementos comuns que se repetem em interações sociais diversas e que podem, por isso mesmo, ser transpostos, mas não "aplicados” em qualquer situação.

Essas interações ocorrem no momento dos encontros intermediados por situações diversas: não por acaso, ao longo de sua trajetória intelectual, Goffman conseguirá trazer essa mirada metodológica para o estudo de situações muito diversas, como reuniões sociais, o comportamento de pessoas internadas em instituições ou mesmo anúncios publicitários.

O "micro" ao qual Goffman dirige seu olhar não parece ser efetivamente a delimitação de um espaço ou grupo, mas o foco nas interações que acontecem dentro de uma situação delimitada - um encontro na mesa de um bar em público ou uma atividade em uma instituição. 
"Micro" não é o tamanho do campo, mas do recorte do olhar sobre o objeto - as interações sociais - em uma dada situação.

Assim, as categorias de Goffman foram essenciais na construção desse instrumento de coleta, no qual combinamos conceitos que o autor apresentou nas obras A Representação do Eu na Vida Cotidiana (1985) e Comportamentos em Lugares Públicos (2010).

Foram adicionados ainda alguns elementos específicos para apreender as relações de poder e como o espaço físico influenciava as dinâmicas - uma parte do instrumento que não tinha relação direta com Goffman, mas que entendemos importantes para investigar as questões formuladas.

Usamos o quadro 1 abaixo para sugerir o caminho da observação em cada encontro e conduzir as anotações que, juntas, formaram o diário de campo deste estudo:

Quadro 1 - Proposições de observação metodológica das interações

\begin{tabular}{|c|c|c|}
\hline Momento & Objetivo & Interações a observar \\
\hline $\begin{array}{l}\text { Preparatório } \\
\text { Forma }\end{array}$ & $\begin{array}{l}\text { Conhecer as con- } \\
\text { dições formais de } \\
\text { realização da inte- } \\
\text { ração do grupo. }\end{array}$ & $\begin{array}{l}\text { Data: } \\
\text { Tipo de interação: ( ) Reunião ( ) } \\
\text { Evento ( ) Workshop ( ) Café } \\
\text { Descrição: } \\
\text { Objetivo comunicacional declarado da } \\
\text { interação: }\end{array}$ \\
\hline $\begin{array}{l}\text { Preparatório 02: } \\
\text { Ambiente, cenário e } \\
\text { participantes }\end{array}$ & $\begin{array}{l}\text { Situar a "cena" } \\
\text { imediata na qual } \\
\text { se desenvolverão as } \\
\text { interações. }\end{array}$ & $\begin{array}{l}\text { Dados do ambiente (cenário): } \\
\text { Participantes e sua posição corporativa/ } \\
\text { nível hierárquico (fachadas sociais): } \\
\text { Nível de formalismo: 1- muito informal } \\
\text { / 2- informal / 3- meio-termo / 4-formal } \\
\text { /5- muito formal }\end{array}$ \\
\hline Início da interação & $\begin{array}{l}\text { Observar os lances } \\
\text { iniciais definidores } \\
\text { das interações. }\end{array}$ & $\begin{array}{l}\text { Jogada de abertura } \\
\text { Lideranças e dianteiras } \\
\text { Níveis de plateia } \\
\text { Divergências e negociações }\end{array}$ \\
\hline
\end{tabular}




\begin{tabular}{|c|c|c|}
\hline $\begin{array}{l}\text { Desenvolvimento da } \\
\text { situação }\end{array}$ & $\begin{array}{l}\text { Compreender as } \\
\text { dinâmicas do mo- } \\
\text { mento a partir das } \\
\text { interações entre } \\
\text { participantes. }\end{array}$ & $\begin{array}{l}\text { Comportamento gestual/postural dos } \\
\text { participantes } \\
\text { Padrões ritualísticos } \\
\text { Falhas de cenário, fachada e represen- } \\
\text { tação (revelação de bastidores ou outros } \\
\text { ruídos) } \\
\text { Tentativa da interação (intencionalida- } \\
\text { des declaradas e tácitas, se for possível } \\
\text { apreender) } \\
\text { Estratégias comunicacionais escolhidas } \\
\text { pela equipe/ator que conduz a interação } \\
\text { Relações de poder entre os participantes } \\
\text { da interação } \\
\text { Ethos do grupo (nível de interesse da } \\
\text { plateia, desempenho dos atores, dinâmi- } \\
\text { cas predominantes, atmosfera formada) }\end{array}$ \\
\hline $\begin{array}{l}\text { Fechamento da si- } \\
\text { tuação de interação }\end{array}$ & $\begin{array}{l}\text { As dinâmicas do } \\
\text { encerramento e as } \\
\text { aberturas de senti- } \\
\text { do resultantes. }\end{array}$ & $\begin{array}{l}\text { Resultados da interação: as estratégias } \\
\text { foram bem-sucedidas? O objetivo foi } \\
\text { cumprido? } \\
\text { Força do ambiente físico e suas confi- } \\
\text { gurações (como concretizam a tentativa } \\
\text { comunicacional?) } \\
\text { Outras observações }\end{array}$ \\
\hline
\end{tabular}

Fonte: elaborado pelos autores

De certa maneira, a densidade dos escritos de Goffman talvez possa ser creditada a essa recusa sistemática pela conceitualização prévia e que busca elaborar uma trama conceitual ao mesmo tempo em que descreve as situações de interação. Daí, dentro de uma chave de leitura, uma característica de seus textos: à primeira vista, trata-se de nada além da descrição de situações corriqueiras, comuns, sem interesse, descritas de maneira aparentemente simples.

Da experiência em campo vale ressaltar que, apesar de ter havido um instrumento de coleta, as anotações foram feitas de maneira livre, sem a amarra do formulário. Durante a observação de um episódio, registrávamos o que julgássemos relevante no caderno: na verdade, o que era possível anotar naqueles momentos, já que a pesquisadora também exercia um papel profissional na interação e não tinha total disponibilidade para fazer os registros. Somente depois da observação 
passávamos as informações para o instrumento, exercício que nos provocava a lembrar de mais detalhes, complementando os dados não anotados primeiramente.

\section{As características das situações de interação}

Entre os meses de agosto de 2018 e fevereiro de 2019, observamos ao todo 12 episódios de interação entre os participantes, realizados no âmbito do Programa, distribuídos da seguinte maneira: três reuniões do "Comitê da Mudança", uma reunião do grupo de gestão, uma conversa no café, um workshop para gestores e funcionários-chave envolvidos com o projeto, uma reunião de trabalho com a consultoria, três eventos internos para toda a organização, uma participação em reunião com a alta direção e uma apresentação para funcionários de um departamento.

Alguns itens foram mais fáceis de captar do que outros, como os padrões ritualísticos, bem marcados em organizações do tipo empresarial. As reuniões, os eventos e os workshops observados, por exemplo, sempre começavam de maneira parecida, com um participante realizando uma apresentação. O mesmo ocorreu na captação das fachadas: as posições hierárquicas e os papéis dos integrantes são bem estabelecidos neste tipo de ambiente social. Foi possível notar, assim, uma repetição intensa nas interações.

Já outros elementos, geralmente ligados à micro-observação, foram difíceis de captar. É o caso do comportamento gestual e postural dos participantes: apesar desta pesquisadora ter registrado algumas manifestações e tal captação ter auxiliado as análises posteriores, houve a sensação de que boa parte dessas expressões não verbais passou despercebida. Como mencionado, acreditamos que a dificuldade resulta da dupla função: a observadora que ao mesmo tempo faz parte daquela organização e desempenha um papel ativo na interação.

Ainda que tenhamos realizado as anotações livremente no caderno, ao final da pesquisa de campo ficamos com a sensação de que o instrumento de coleta foi de grande auxílio para guiar o olhar, mas ao mesmo tempo um limitador: diversos movimentos dos participantes e detalhes 
da interação podem ter sido ignorados por conta deste direcionador, que possivelmente pré-moldurou o exercício de apreensão.

Também vale ressaltar o esforço contínuo para, na medida do possível, se afastar e observar a cena, ainda que estivéssemos nela. No diário de campo, registramo-nos como participante, anotando as próprias manifestações e papéis assumidos ao longo da interação. É como se a persona "observadora" estivesse registrando os movimentos da persona "analista de comunicação": essa foi a tentativa.

Certamente, em suas obras, Goffman reserva um considerável espaço dedicado à descrição de situações, interações, atitudes e comportamentos. Esse procedimento parece estar quase sempre ligado à possibilidade de apreensão crítica imediata para, a partir daí, construir uma análise: talvez não seja de todo errado observar nisso certa herança fenomenológica, ainda que indireta, relacionada à condição de pensar a descrição do fenômeno como primeira etapa de sua apreensão, partindo em seguida para a reflexão crítica sobre o empírico.

Esse procedimento parece ocupar um considerável espaço em todas as obras de Goffman: com exceção de Os quadros da experiência cotidiana, Goffman raramente desenvolve uma obra a partir de uma elaboração conceitual mais filigranada, preferindo, na maior parte das vezes, construir uma trama conceitual a partir do que mostra uma situação analisada. A perspectiva metodológica de Goffman parece se ancorar, entre outros fatores, na percepção dos fenômenos mediada, o tempo todo, pelo trabalho analítico de abstração a partir do qual são construídos os conceitos que, por sua vez, contribuem para a interpretação do objeto.

No entanto, à medida que Goffman se dirige ao detalhamento dessas situações, o descritivo reveste-se de caráter analítico e, mais para frente, conceitual, revelando nuances desconhecidas, ou mesmo deixadas de lado, no momento inicial ou na observação assistemática. Isso leva a ver outros ângulos do objeto, retrabalhado à exaustão em cada uma de suas pesquisas até que sua apreensão compreensiva seja completa. 
A produção de sentidos comunicacionais, em Goffman, parece se desenvolver em termos de uma apreensão global de situações a partir da costura dos mínimos elementos presentes em uma situação de interação, o que não exclui a interação de leitura - além do prefácio mencionado, esse tipo de microleitura da produção de sentidos acontece também em Gender Advertising ou em Forms of Talk.

A descrição, nesses casos, é problematizada em relação ao conjunto maior no qual estão inseridos - isto é, a pesquisa desenvolvida por Goffman em determinado momento, seja no espaço delimitado de um hospital, seja na delimitação de um tipo específico de interação.

Observando um episódio de interação face a face, foi surpreendente perceber como as categorias de Goffman funcionam bem como instrumento de observação. A separação entre a equipe de atores e a plateia, os elementos do espaço físico configurados em um cenário, as pessoas assumindo fachadas, os níveis de interação da plateia (ativa ou espectadora), os engajamentos de face e o ethos que se forma no grupo; todos esses conceitos emolduram o que está sendo observado na cena.

Pelas fachadas conseguimos apreender as relações de poder entre os participantes e como cada comportamento é, de certa forma, dado pelo papel que se assume. Por exemplo: enquanto os gestores se sentiam mais confortáveis para falar, divergir e negociar, os analistas atuavam como "coro" de seus chefes, complementando seus pontos de vista. Como afirma Velho (2008, p. 146), "os indivíduos desempenhando papéis estão sempre procurando expressar-se e, para que isso tenha sucesso sociopsicológico, é necessário que os atores com quem estejam interagindo se impressionem com o que está sendo transmitido".

Por fim, a análise conjunta das cenas nos possibilitou identificar algumas regularidades, no sentido indicado por Bourdieu (1990), que, não sem algo de paradoxal, singularizavam o conjunto de interações. O quadro 2 procura identificar essas observações: 
Quadro 2 - Percepções metodológicas das interações observadas

\begin{tabular}{ll}
\hline Momento & Característica Interacional \\
\hline Ritual & $\begin{array}{l}\text { Há um procedimento ritualístico bem definido em cada } \\
\text { tipo de interação, que se repete nas interações. }\end{array}$ \\
\hline $\begin{array}{l}\text { Espaço físico regula o nível } \\
\text { de interação }\end{array}$ & $\begin{array}{l}\text { Na sala de reunião a conversa/diálogo é mais intensa do } \\
\text { que nos espaços organizados em auditório. }\end{array}$ \\
\hline Hierarquia dosa a expressão & $\begin{array}{l}\text { Regra social implícita determina quem pode se expres- } \\
\text { sar mais (presidente/gestores) e quem pode se expressar } \\
\text { menos (demais funcionários). }\end{array}$ \\
\hline Ethos & $\begin{array}{l}\text { Cada episódio interacional forma um ethos ou espírito } \\
\text { único. Ainda que o cenário e os atores sejam os mesmos, } \\
\text { uma interação jamais é igual à outra. }\end{array}$ \\
\hline Estratégia & $\begin{array}{l}\text { Apesar de haver uma jogada de abertura ritualística, as } \\
\text { estratégias comunicacionais acionadas pelos participan- } \\
\text { tes são singulares em cada episódio, pois são formuladas } \\
\text { e aplicadas a partir da reação dos outros. }\end{array}$ \\
\hline
\end{tabular}

Fonte: elaborado pelos autores

Isso permite talvez retomar o que foi dito acima a respeito de sua elaboração conceitual: se há o que parece ser uma unidade no olhar metodológico, que busca incidir sobre as interações sociais, a especificidade de cada uma delas desafia a formulação de uma teoria geral ao mesmo tempo que permite a observação, em cada nova pesquisa, de novas nuances do que está sendo visto. Utilizando uma definição epistemológica formulada por Vera França (2014), seria possível dizer que o olhar de Goffman incide sobre diversos objetos empíricos - comunidades, instituições, locais públicos - no sentido de aperfeiçoar e filigranar aspectos de seu objeto de conhecimento, as interações sociais.

Conceitos como o de "palco" e "bastidor", "enquadramento" ou "instituição total”, empregados em algumas de suas obras principais, retornam esporadicamente, mas não se constituem como um repertório conceitual e hermenêutico apto a ser aperfeiçoado na medida em que se tornam presentes, ou ao menos visíveis, em situações específicas. 
Ao que parecem, em Goffman os conceitos estão em constante choque com uma realidade que se mostra inapreensível em sua generalidade, mas que, ao mesmo tempo, revela algumas repetições, semelhanças e mesmo "padrões" - palavra usada aqui com cuidado, referente a uma herança da antropologia de origem em Goffman - em sua escala de observação, o espaço microssocial.

\section{Considerações finais}

A microssociologia de Goffman não parece se referir propriamente ao tamanho das situações analisadas, mas ao olhar metodológico dirigido aos momentos de interação, sublinhando cada uma de suas filigranas, nuances e detalhes responsáveis pela construção dos sentidos - a comunicação - na relação com os outros. Em Goffman parece haver todo um mundo a desvelar no insignificante - categoria, por sua vez, que aparentemente deixa de existir dentro de sua perspectiva metodológica, uma vez que os detalhes se tornam, muitas vezes, protagonistas das situações de interação.

Isso leva a outra questão: em que se constitui, efetivamente, a delimitação do espaço de observação em Goffman? É relativamente comum ver o nome de Goffman associado à ideia de "microssociologia”, da qual ele seria o criador e, por considerável tempo, único representante. É possível questionar, em termos metodológicos, o que pode existir efetivamente de "micro" em suas análises. Para tanto, vale retomar alguns aspectos de suas elaborações e interesses teóricos.

$\mathrm{Na}$ medida em que estes conceitos nascem da pesquisa de campo sistemática, e são por ela informados, retomados e corrigidos, poderia existir, em uma leitura inicial, a tentativa de classificar Goffman como um empirista pouco interessado na elaboração de um repertório teórico-crítico em relação à realidade observada. No entanto, essa sua busca pelo empírico não o encerra em termos do que poderia ser considerado um relato do momento ou do material observado.

A observação das questões metodológicas envolvidas na observação das microinterações não deixa de se apresentar dentro de uma 
perspectiva mais ampla que se revela nessa escala, como ressalta Maria Teresa S. Garraza (2001). Em sentido semelhante, Camila P. Castro (2012, p. 204) assinala algumas perguntas como perguntas motivadoras do trabalho elaborado a partir de Goffman: "que princípios estruturais informam contatos rituais nas interações? Ou ainda, como as características da ordem da interação podem ser conectadas a estruturas sociais?".

A análise das interações em escala micro no contexto organizacional, na perspectiva de Goffman, parece requerer uma discussão metodológica sempre renovada, sobretudo na medida em que o método, como recorda Lucrécia D’A. Ferrara (1996), não se constitui como conjunto de técnicas ou receituário, mas a composição de indagações elaboradas no enfrentamento do real que se procura estudar. Dessa maneira, não se fala aqui do "método em Goffman" ou em uma "metodologia" a partir do autor, mas procurar pensar "com" algumas de suas perspectivas.

Carlos B. Martins (2008, p. 140) ressalta que "tais relações que os indivíduos travam entre si em situações sociais concretas constituem um domínio de investigação analiticamente distinguível - a ordem de interação -, que possui estruturas, processos e regularidades específicas, não podendo ser reduzida a situações macrossociais e cujo método adequado de investigação repousa na microanálise”.

A prática metodológica de Goffman parece oferecer uma perspectiva metodológica na qual o conhecimento é construído a partir do respeito às características próprias de cada situação, articuladas com sua proposta de ver, aí, os procedimentos de interação social.

Não há, portanto, o que poderia ser visto como uma espécie de solipsismo do objeto empírico na análise de Goffman, algo que impediria qualquer desenvolvimento posterior, mas a busca por um cuidado metodológico que respeite as características das interações presentes em cada situação de pesquisa ao mesmo tempo que permite observar, em contraste e tensionamento, alguns dos elementos já apontados por ele em suas pesquisas: assim, não parece ser possível "aplicar Goffman", algo que nem ele mesmo fazia, como sugere sua recusa em transpor conceitos entre obras, mas construir um olhar metodológico "a partir de 
Goffman" como procedimento epistemológico na prática de pesquisa em Comunicação.

\section{Referências}

BLITVICH, P. G-C. Face, identity and im/politeness. Journal of Politeness Research, v. 9, n. 1, p. 1-33, 2013.BOURDIEU, P. Erving Goffman, descobridor do infinitamente pequeno. In: GASTALDO, E. (Org.). Erving Goffman, desbravador do cotidiano. Porto Alegre: Tomo Editorial, 2004.

BOURDIEU, P. Questões de Sociologia. Rio de Janeiro: Marco Zero, 1983.

BRAGA, J. L. Dispositivos Interacionais. Trabalho apresentado no $20^{\circ}$ Encontro da Compós. Anais... Porto Alegre: UFRGS, junho de 2011.

BRAGA. J. L. A prática da pesquisa em Comunicação: abordagem metodológica como tomada de decisões. E-Compós, v. 14, n. 1, jan.-abr., 2011.

BRANDÃO, C. R. Pesquisa Participante. São Paulo: Brasiliense, 1999.

CASTRO, C. P. Ordem da interação, embaraço e agência do self na obra de Erving Goffman. Teoria e Sociedade, v. 1, n. 20, p. 198-2017, jan.-jun., 2012.

CORAZZA, S. M. Labirintos da pesquisa, diante dos ferrolhos. In: COSTA, M. V. Caminhos investigativos. Porto Alegre: Ed. Mediação, 1996.

DYNEL, M. Revisiting Goffman's postulates on participant statuses in verbal interaction. Language and Linguistics Compass 5/7 (2011): 454-465

FERRARA, L. D’A. Olhar periférico. São Paulo: Edusp, 1996.

FERREIRA, D. A. Ator sincero e ator cínico: a análise das interações comunicacionais no contexto organizacional a partir da perspectiva dramatúrgica de Erving Goffman. Dispositiva, v. 7, n. 11, p. 123-137.

FERREIRA, D. A. Os estudos de representações sociais e suas contribuições para o entendimento das estratégias de interação no contexto das organizações. Trabalho Apresentado no $11^{\circ}$ Abrapcorp. Belo Horizonte: Anais... 15 a 19 de maio de 2017.

FLECHA, V. O.; MACHADO, M. N. M. Organização, controle e representação: estudo de um processo de interação entre consultor e empresário. Trabalho apresentado no XXXII Encontro da Anpad. Anais... Rio de Janeiro: 6 a 10 de setembro de 2008.

GAJARDO, M. Pesquisa participante na América Latina. São Paulo: Brasiliense, 1986. GAMA, M. G. A fabricação da imagem social da empresa. Atas do IV SOPCOM. Minho: Sopcom, 2005.

GARRAZA, M. T. S. Origen, aplicación y limites de la "Teoria del encuadre" en comunicación. Comunicación y Sociedad, v. XIV, n. 2, p. 143-175, 2001.GASTALDO, E. Goffman e as relações de poder na vida cotidiana. Revista Brasileira de Ciências Sociais, v. 23 , n. 68 , p. 149-153, out. 2008. Introdução. In: (Org.). Erving Goffman, desbravador do cotidiano. Porto Alegre: Tomo Editorial, 2004.

GOFFMAN, E. A representação do eu na vida cotidiana. Petrópolis: Vozes, 1985.

Comportamento em lugares públicos. Petrópolis: Vozes, 2014.

Os quadros da experiência social. Petrópolis: Vozes, 2010. 
Rituais de interação. Petrópolis: Vozes, 2011.

LEEDS-HURWITZ, W. Erving Goffman as communication theorist. Trabalho apresentado no Encontro Anual da Associação Internacional de Comunicação. Nova Orleans: Anais... Nova Orleans, 2004.

LÜDKE, M.; ANDRÉ, M. L. L. Pesquisa em Educação: abordagens qualitativas. São Paulo: E.P.U., 1996.

MARTINELLI, M. L. O uso de abordagens qualitativas em serviço social. In:

Pesquisa Qualitativa: um instigante desafio. São Paulo: Veras, 1999.

MARTINO, L. M. S.; MARQUES, A. C. S. A afetividade do conhecimento na epistemologia. Matrizes, v. 12, n. 2, p. 217-234, maio-ago. 2018.

MARTINO, L. M. S. Métodos de Pesquisa em Comunicação. Petrópolis: Vozes, 2018.

MARTINS, C. B. Notas sobre o sentimento de embaraço em Erving Goffman. Revista Brasileira de Ciências Sociais, v. 23, n. 68, p. 137-143, out. 2008.

NIZET, J.; RIGAUX, N. A sociologia de Erving Goffman. Petrópolis: Vozes, 2016.

SANDERS, R. The representation of self through the dialogic properties of talk and conduct. Language and Dialogue 2:1 (2012), 28-40.

SANTOS, A. P. Dispositivos interacionais no ambiente organizacional. Trabalho apresentado no III Seminário Internacional Midiatização e Processos Sociais. São Leopoldo: Unisinos, 6 a 11 de maio de 2019.

SCHEGLOFF, E. A. Goffman and the analysis of conversation. DREW, P.; WOOTTON, T. Erving Goffman: exploring the interaction order. Cambridge: Polity, 1988, p. 79-93.

VELHO, G. Goffman, mal-entendidos e riscos internacionais. Revista Brasileira de Ciências Sociais, v. 23, n. 68, p. 144-148, out. 2008, p. 144-148.

VIANNA, H. M. Pesquisa em educação: a observação. Brasília: Aeroplano, 2003.

WINKIN, Y. A nova comunicação. Campinas: Papirus, 2004.

Apresentação. In: (Org.). Os momentos e seus homens. Lisboa: Relógio

D’Água, 1999.

WINKIN, Y.; LEEDS-HURWITZ, W. Erving Goffman. Londres: Peter Lang, 2012.

YTREBERG, I. Goffman as media theorist. Critical Studies in Media Communication, v. 19, n. 4, p. 481-497, dez. 2002.

\section{Sobre os autores}

Luis Mauro Sá Martino - Formado em Jornalismo pela Cásper Líbero, fez Mestrado e Doutorado em Ciências Sociais na PUC-SP, com pós-doutorado na Universidade de East Anglia (Norwich, UK) em 2008. Na Cásper Líbero, 
é professor de Comunicação Comparada no Curso de Jornalismo desde o ano 2000. É professor e pesquisador do Mestrado, vinculado à Linha de Pesquisa "Processos Midiáticos: Tecnologia e Mercado", e lidera o Grupo de Pesquisa "Teorias e Processos da Comunicação".

Ana Paula Santos - Mestranda em Comunicação pela Cásper Líbero

Data de submissão: 28/06/2019

Data de aceite: 03/03/2020 